\title{
A semiotic exploration of catastrophes in game worlds
}

Research Article

Mattia Thibault

Tampere University

Received 27 April 2019; Accepted 17 August 2019

\begin{abstract}
The aim of this paper is to overview the presence of catastrophes in game worlds and, in particular, to investigate what they can tell us about real catastrophes. To this end, we present a semiotic typol-ogy of catastrophes, confronting them with epistrophes and apostrophes and further articulating them relative and absolute cessation events. Then we highlight the long-standing relationship between playfulness and disasters in literature, cinema and video games underlining how the suppos-edly opposite characteristics of the two are, in fact, a very productive cultural trope. To conclude, we look into some examples of catastrophes in game worlds, both relative (such as the "corrupted blood incident" in World of Warcraft) and absolute (the end of the worlds in StarWars Galaxies and Matrix Online).
\end{abstract}

Keywords: Catastrophe $\bullet$ Epistrophe $・$ Apostrophe $・$ Virtual world $\bullet$ Play world

(C) Sciendo

\section{Introduction}

"Catastrophe" is an elusive object of study that has often been approached with a semiotic sensibility, for example, in the works of Thom and Petitot [1-7], De Martino [8], Muzzoli [9], Marotta and Zirilli [10] and Idone Cassone et al. [11]. The term, which in itself means "overturning", is used, from time to time, as a synonym for "end of the world" or simply "disaster". In the first case, the catastrophe must confront a series of terms religiously loaded such as "apocalypse" (or "revelation", the one received by St. John about the end of time and of the second coming of Christ) or "Armageddon" (toponym of the place where, in the book of the Apocalypse, armies gather for the final battle). In the second case, it becomes synonymous with destruction and cataclysm (literally "flooding"), i.e. destructive events that leave behind ruins - another keyword of this semantic field, see Leghissa [12] - upon which it will be possible, in some cases, to rebuild a new order. In both cases, the catastrophe is configured as a discontinuity that is inserted in an unexpected and violent way in a pre-established continuity.

Reformulating the question in semiotic terms, we can identify this continuity with the effect of meaning arising from the relative social stability of a human community and from the repetition that characterizes their biological, economic, cultural and sign production and reproduction. This continuity, therefore, is structured as a narrative program, cyclical and social, which gives life to a series of expectations and predictions about the flowing events: it is what we commonly call "everyday life", "routine" and the like.

Obviously, it is not uncommon that the actual succession of events differs considerably from the expected narrative program of everyday life, sometimes due to events anticipated well in advance or other times due to unforeseen or unexpected accidents. Starting from the actual convergence between the unfolding of events and the narrative program of daily life, we can distinguish between three situations:

- The Epistrophe or convergence: events follow the predicted trajectory without disturbing the routine. The flow of events fits roughly with the social narrative program (including also extra-ordinary, but expected, events such as weddings and births that are then engraved in the routine through anniversaries and recurrences).

- The Apostrophe or divergence: something disturbs the succession of events. An unexpected accident makes the events diverge from the narrative program, bringing the community or the individual out of the domain of everyday life. 
- The Catastrophe or overturning: the succession of events abruptly moves away from the narrative program and questions the very possibility of recreating a new continuity.

We can note that we have not postulated euphoric or dysphoric values for the apostrophe. Logically, therefore, a beneficial event such as winning a lottery may constitute an apostrophe. The catastrophe for its part, threatening the very possibility of a return to some kind of continuity, often has a dysphoric character - although the latter is often a matter of perspective. This is particularly relevant if the destruction is caused by the encounter or clash between two communities. The extermination of American Natives is undoubtedly a catastrophe if we look at it from a narrative that sees them as subjects and the European settlers as opponents. If, however, we decide to follow the opposite narrative, the one where white pioneer are the subjects and the "redskins" the opponents, we no longer have a catastrophe but a history of victory and conquest. The filmography on the topic is more than enough to outline the picture. In films such as Northwest Passage (by King Vidor, 1940), Natives are the villains, often portrayed as barbarians without culture (as typical of the perspective of cultures oriented towards content, according to Lotman et al. [13]) and with features juxtaposed to those of the "civilised white men" [14]. On the other hand, films such as Dance with Wolves (by Kevin Kostner, 1990) adopt a romantic perspective based on the bon sauvage by Montaigne.

It is possible that it is precisely for this indeterminacy that the term "catastrophe" is used more often to indicate "natural" events, disasters whose agency does not refer to any embodied actor except in rare cases.

Likewise, the boundary between apostrophe and catastrophe is also a question of perspective and interpretation. Generally, the difference between the two is identified in their magnitude. This, however, is an extremely subjective criterion: how to identify a threshold above which the mishap becomes a catastrophe? We must recognize, then, that the difference between the two lies in the interpretation that a community gives to a specific event.

We can define the catastrophe, then, as an event that is perceived by a community of interpreters as a sudden, violent and unexpected deviation from the narrative program of everyday life, capable of threatening the very existence of the latter. If the apostrophe, on one hand, is typically perceived as a pausative event, the catastrophe, on the other hand, is ceasative. In this regard, we can make a further distinction between relative-cessation events and absolute-cessation events.

(1) Relative cessation implies an interruption of continuity that leaves open the possibility, however difficult, of a return to some kind of new normality, the return to a state of equilibrium irremediably different from the initial one.

(2) Absolute cessation, on the other hand, excludes any possibility of reconstruction. After an absolutecessation catastrophe, there is nothing left: Earth is destroyed and humanity is extinct.

This last distinction does not simply concern the dynamics of the catastrophe but is decisive for identifying the ways in which it acquires a meaning. Relative-cessation catastrophe, generally, acquires their meaning a posteriori. What we have referred to as the "succession of events", in fact, once semiotised, is nothing but a form of life [15]: a set of events that, in retrospect, are articulated on the process axis in order to make sense.

An absolute-cessation catastrophe, however, can only be postulated, hypothesized or feared: its very nature prevents any subsequent interpretation, excluding the survival of any interpreter. This second type of catastrophe, therefore, is often positioned in the future, awaited with millenarian faith, ridiculed by sceptics, predicted by unheard scientists. In this case, the catastrophe is no longer understood as a concrete event that is "read" as such but as an ideological device that builds an ultimate horizon of existence.

All the types of catastrophes that we have outlined in this paragraph, both absolute and relative ones, are often the object of cultural, discursive and narrative representations; either religious (the Deluge and the Apocalypse), scientific (global warming and the end of the universe) or related to entertainment (the examples in this case are countless).

In this paper, however, we will deal with a particular type of catastrophe, which is not purely narrative even though it does not take place in the "real" world. I refer to the catastrophes that occur in virtual worlds. These are worlds populated by human beings - or rather by actors composed, in part, by instances of human origin articulated around virtual spaces that can be presented as parallel to everyday life (as in Second Life or, more recently, VRChat) or, more often, digital game worlds linked to massively multiplayer games (MMOs).

These catastrophes are interesting case studies for several reasons. First of all, because they have to do with the only non-purely narrative worlds of which we can study the end: absolute-cessation catastrophes, in fact, although they completely destroy these worlds and their virtual inhabitants, obviously do not affect the users who inhabit 
them or the texts that had been transferred from these worlds to ours (for example in the form of screenshots). Second, these are worlds that are relatively simple to monitor and understand thanks to their nature of trackable digital constructs. Unlike the real world, more or less everything that is present in virtual worlds is artificially crafted, and therefore explained by the design logic that has been implemented by its creators.

\section{Games that kill and catastrophic settings}

\subsection{Playfulness and catastrophe}

Playfulness and catastrophe would seem to be two areas very far from each other. Where playfulness is often (but not always!) described as not serious, reversible [16] and creative, catastrophes are very serious, irreversible and destructive.

Nevertheless, numerous narratives seem to closely link these two concepts. There are many examples of films or books set in post-apocalyptic situations in which some games emerged as a primary tool for organizing the world and managing the conflict. In Robert Altman's Quintet (1979), the inhabitants of a world devastated by atomic winter, now incapable of having children, spend their time playing a complex board game that involved, after the game, a series of murders between players. A more recent example is the "Hunger Games" series by Suzanne Collins, transposed to the big screen by Gary Ross in 2012, in which deadly pseudo-gladiatorial games are the basis of the social pact that maintains the unstable order of the dystopian state of Panem. In both these cases, the game is proposed as a new regime of meaning that takes the place of the one destroyed by a catastrophe that we see only in its consequences. In a world in which the sense of things has been lost, macabre and deadly play is presented as the only semantising force. Seriousness does not make sense any more, and everyday life becomes a deadly joke, in which play becomes "serious" and irreversible.

Other narratives depict play as a social engine for future worlds in which the catastrophe has been only moral but equally desemantising. In the film La decima vittima by Elio Petri (1965), a bored future society follows in a reality show ante litteram a game called "the big hunt" in which people randomly chosen by a computer must kill each other in order to win a final money prize. The carnivalesque band of the "Droogs" in A Clockwork Orange (a novel by Antony Burgess, 1962, and later a film by Stanley Kubrick, 1971) is equally a symbol of the ethical catastrophe of the dystopian future presented by the film: their behaviour, sadistic and cruel, is also presented as playful, carnivalesque and grotesquely joyful. In Ready Player One (novel by Ernest Cline, 2011, and film by Spielberg, 2018), the void of meaning left by extreme capitalism is filled with escapist play in a virtual world that becomes the primary reality for a large part of the population and the only real space of value for the characters to fight for.

Play is not only portrayed as a consequence of the catastrophe, but it is sometimes its cause. In Wargames by John Badham (1983), an artificial intelligence risks global annihilation by believing that it is playing a game called "global thermonuclear war" and is only stopped when the protagonists teach it that there are games in which it is impossible to win, using "tic-tac-toe" as an example. Two years later in the novel Ender's game (by Orson Scott Card), the eponymous protagonist commits a planetary genocide being convinced that he is only participating in a simulation, while what he believed was just a game was the unfolding of a real battle. In these narratives, it is the belief that games are reversible to cause (or risk causing) the catastrophe. The narratives are centred on the diametrically opposed features of play - defined as inconsequential, a form of pretending - and of the catastrophe - that instead is highly consequential, as it menaces the possibility of re-establishing a continuity of events. The adoption of play as the main approach to make sense of the world becomes a source of catastrophic consequences, while the "pretend" inevitably becomes "for real", revealing to what lengths we are ready to go in order to win a game.

\subsection{Playing the catastrophe}

Given the fruitfulness of this juxtaposition, it is not surprising that also digital games make extensive use of the catastrophe as a narrative tool or as a setting. Many important titles put players in front of an imminent apocalypse that threatens to destroy the diegetic world they have come to know and love in tens or hundreds of hours of play (for example, in the Mass Effect series, BioWare). Other games are set after a global catastrophe, such as the Fallout (Bethesda) series, which allows players to explore in detail a post-apocalyptic America with a distinctly 1950s and 1960s style. Finally, there are games that implement the catastrophe as the core of game mechanics: 
players might have to prevent it (like in Fate of the World, by Red Redemption, 2012, see also Idone Cassone [17]) or to cause it (this is the case of Plague Inc., by Ndemic Creations (2012), where the player must create and change an infection capable of zeroing the human population on the planet, see Mitchell and Hamilton [18]).

In all these cases, however, we are dealing with diegetic disasters, i.e. disasters affecting the narrative play world of a game and that are only reflected or portrayed by its virtual simulation. Sometimes, however, it is the latter that is the subject of catastrophes, from real digital epidemics to true ends of the world.

\section{The end of virtual worlds}

Many types of digital games present a virtual world. In single-player games, these are explored and experimented in parallel by each player, acting through an avatar in a world populated only by bots moved by the computer. Multiplayer games, as the name suggest, allow the presence of multiple players simultaneously in the same virtual world, where they can interact in a collaborative or competitive way depending on the nature of the game. The most interesting virtual worlds, however, are those of MMO games: virtual worlds shared by thousands - sometimes millions - of players. These virtual places remain active unceasingly from the launch of the game, constantly online hosting the avatars of the players and their actions. In these spaces, the games propose to the players both repetitive play narrations (which each player or group of players can go through individually) and other wider narratives, which are not repeated but develop over a period that can last years and affect all the players.

Considering MMOs as virtual worlds "separate" from the real one is a problematic habit, as pointed out by Lehdonvirta [19]. In fact, what we are confronting is a multi-layered semiotic artefact. On the one hand, we have a game narrative that projects a possible world [20] around itself. This is a purely interpretative entity and exists only in the minds of the players and designers. The digital virtual world is a diagram of that possible world, a toposensitive, iconic representation of it. As a functive of a sign function, a signifier, it obviously exists in the "real" world, but with an effect of trompe-l'oeil invites the players to go "inside" it and to pretend that it is an elsewhere [21]. Owing to the interactive nature of games, however, the digital virtual world is also a space where players can act and interact. Players can behave within this space in multiple ways, adhering or contradicting the possible world proposed by the narrative of the game, bringing along instances from the "real world", transforming it in a playground and using what it contains as toys to play different games.

When it comes to our investigation of catastrophes in these virtual worlds, as mentioned, we are not interested here in the diegetic disasters that occur in these worlds - those that happen in the possible worlds and are mirrored in the virtual representation - but on those that invest the virtual world as an artefact, which affects directly the signifier.

There are several examples both of relative and absolute-cessation catastrophes in these spaces.

Regarding the relative-cessation catastrophes, the best known and studied case is that of the "corrupted blood incident" occurred in World of Warcraft. Owing to a programming error in September 2005, for a whole week the virtual world of the game was scourged by an epidemic causing the death of hundreds of avatars. What was supposed to be a new game mechanic relegated to a small part of the virtual world - a disease that hit the avatars in a dungeon making a specific quest more complex - turned into a global threat, infecting thousands of avatars and causing panic among the players. This catastrophe, therefore, escaped the diegesis and nested into the virtual world, exploiting its digital nature to expand.

What is more interesting is that several epidemiologists, including Professor Balicer [22] from Ben-Gurion University, found that the behaviour of players during the unintended outbreak was exceptionally similar to how people behave in real-life epidemics: some players used their healing skills to help others, some players escaped from the infected areas - especially cities - taking refuge in the countryside and some, finally, did their best to spread the disease more and more. While this virtual catastrophe occurred in a play world, it still became a subject of some studies and academic publications. After several attempts at containment, the editors of the game managed to put an end to the crisis by "resetting" the world and thus saving it - something that unfortunately cannot be done in the real world.

The absolute-cessation catastrophes of virtual worlds, however, are not generally due to programming errors but occur when a game is terminated, for reasons of budget (for example due to the decrease in the number of active and paying players) or because the owners decide to move resources to other projects. Of more than 1000 MMO games created since the 1990s, approximately 300 have been closed. Three hundred virtual worlds have 
gone through a real apocalypse and have vanished into thin air, cancelled by the servers that had hosted them until then.

In most cases, these disasters are minimalistic and ruthless: the servers are taken offline, and the virtual world is simply erased and annihilated. Sometimes, however, the preparation and execution of the catastrophe take different forms, allowing avatars, and the players who move them, to experience them, live them and understand them. Partin [23] describes two of them, chosen because - unlike many others - they proposed a sort of organised closure also within the digital world itself.

The first example is that of Star Wars Galaxies, launched in 2003 and closed three years later, in 2006 by Sony Online Entertainment. The game, set in the galaxy of the well-known franchise, did not offer players adventures or spectacular narratives but allowed them to "live" in a science fiction world, where their characters could devote themselves to humble work (such as baristas or spaceship construction workers). This game dynamics had helped to build a sort of unusually cohesive society, in which the characters frequently interacted and built solid bonds.

When the time came, as a sort of reward for the players who remained loyal to the game until it reached its hour, the developers decided to celebrate the apocalypse with a fireworks display (which put a strain on slower connections) and declared the players with the highest scores as "winners" - a rather unusual occurrence, since there is generally no victory in MMOs.

Players whose avatars were present before the catastrophe describe the last hours of the game as carnivalesque and unbridled: abandoning any diegetic coherence, the characters danced on the streets in their underwear and gave their precious belongings (accumulated after long hours of play) to anyone who wanted to toy with them. Several groups of friends who met in game had farewell gatherings. Some players, like the journalist Thursten [24], programmed a romantic exit in the last seconds before the end of the world, synchronizing a last "jump in hyperspace" with the final suspension of the servers, in order to have the impression of starting a new journey before the message "You cannot connect to that Galaxy at this time. Please try again later" signalling the irremediable end of the world.

Less romantic but just as interesting is the final cataclysm of The Matrix Online, a game that survived four years between 2005 and 2009. The apocalypse, in this case, was announced with a very short notice to the players and was realised by staging a virtual blood bath. Shortly before the servers were disconnected, every location of the game was invaded by unbeatable monsters who mercilessly hunted down the avatars, which suddenly were no longer able to "resuscitate". The few survivors of the massacre, concentrated in the last safe zones of the virtual world, met an even worse destiny - captured on video by some player: an artefact of virtual archaeology testifying of the last moments before the end.

In the video ${ }^{1}$ we see a dozen avatars gathered in a virtual square waiting for the end. Most of them are dressed in black or white, as can be expected in this setting, with the exception of the always-present character that shows up on the judgement day wearing only its underwear: inevitable exhibitionism that celebrates the end of the social norms and, together, of the diegesis. After a few moments of silence, electric shocks appear among the characters, who suddenly start to utter atrocious screams and wriggle up on themselves, lying then in inert ground. The only survivor is a black cat, an involuntary (?) citation of the first film in the series. Finally, a message reported a connection error thus confirming that the servers had been turned off forever. Someone comments (another quote from the movie): "not like this ... not like this ...".

It is hard to say how much these virtual ends of the world can tell us about real disasters and how people could react to them. Partin [23] argues that "What is unique and valuable about the end of an MMO is that it can also be a kind of 'real' event that is the right of representation, the destruction of an imagined world". Indeed, the suppression of the virtual world of MMO games does not represent an end of the world, but it is one. If it certainly cannot tell us how humanity will deal with the apocalypse, it is, however, the situation closest to it that we can experience, although in a mediated way. The advantage is that, after it has happened, we are still here, and we can observe it, study it and use it as a starting point for reflection.

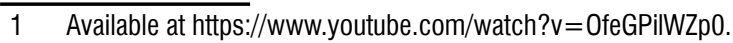


[1] Thom, R., 1972. Langage et catastrophes: Eléments pour une sémantique topologique. In Peixoto, M.M. (Ed.), Symposium on Dynamical Systems, Bahia, 15 Luglio. New York: Academic press, pp. 619-654.

[2] Thom, R., 1983. Paraboles et catastrophes: entretiens sur les mathématiques, la science et la philosophie. Flammarion: Paris.

[3] Thom, R., 1988. Esquisse d'une sémiophysique. Paris: InterEditions.

[4] Petitot, J., 1979. Hypothèse localiste et théorie des catastrophes. Note sur le debat. In M. Piatelli Palmerini (Ed.), Théories linguistiques et théorie de l'apprentissage. Paris: Seuil, pp. 516-524.

[5] Petitot, J., 1985. Les catastrophes de la parole de Roman Jakobson à René Thom, Paris: Maloine.

[6] Petitot, J., 1990. Morfogenesi del senso: per uno schematismo della cultura. Milan: Bompiani.

[7] Thom, R., Petitot, J., 1983. Sémiotique et théorie des catastrophes, Actes semiotiques, Documents du Groupe de Recherches Sémio-linguistiques, E.H.E.S.S. - C.N.R.S. Besançon: Institut National de la Langue Français.

[8] De Martino, E., 1977. La fine del mondo. Contributo all'analisi delle apocalissi culturali. Turin: Einaudi.

[9] Muzzoli, F., 2007. Scritture della catastrofe. Rome: Meltemi.

[10] Marotta, N., Zirilli, O., 2015. Disastri e catastrofi, Santarcangelo di Romagna: Maggioli.

[11] Idone Cassone, V., Surace, B., Thibault, M. (Eds.), 2018. I discorsi della fine. Catastrofi, disastri, apocalissi. Roma: Aracne.

[12] Leghissa, G., 2018. Le rovine e le catastrofi della storia. Considerazioni su una metafora influente. In Idone Cassone, V., Surace, B., Thibault, M. (Eds.), I discorsi della fine. Catastrofi, disastri, apocalissi.
Roma: Aracne, pp.: 223-234.

[13] Lotman, Y., Uspensky, B.A., Mihaychuk, G., 1978. On the semiotic mechanism of culture. New Literary History, 9, 211-232.

[14] Lancioni, T., 2009. Immagini narrate Semiotica figurativa e testo letterario. Milano: Mondadori.

[15] Fontanille, J., 2015. Formes de vie. Liegi: Presses Universitaires de Liège.

[16] Caillois, R., 1967. Les Jeux et les hommes. Paris: Gallimard.

[17] Idone Cassone, V., 2018. Erase \& Rewind. Esplorando le catastrofi simulate. In Idone Cassone, V., Surace, B., Thibault, M. (Eds.), I discorsi della fine. Catastrofi, disastri, apocalissi. Roma: Aracne, pp.: 165-180.

[18] Mitchell, S., Hamilton, S.N., 2018. Playing at apocalypse: Reading Plague Inc. in pandemic culture. Convergence, 24, 587-606.

[19] Lehdonvirta, V., 2010. Virtual worlds don't exist: Questioning the dichotomous approach in MMO studies. Game Studies, 10.

[20] Eco, U., 1979. Lector in fabula. Milano: Bompiani.

[21] Calabrese, O., 2011. L'arte del trompe-l'oeil. Milano: Jaka Book.

[22] Balicer, R., 2005. Modeling infectious diseases dissemination through online role-playing games. Epidemiology, 18, 260-261.

[23] Partin, W., 2016. When a video-game world ends. The Atlaintic, 12 January 2016. Available at: https://www.theatlantic.com/entertainment/ archive/2016/01/when-a-video-game-worldends $/ 423360 /$.

[24] Thursten, C., 2011. Inside the final hours of Star Wars: Galaxies. PC Gamer, 16 December 2011. Available at: https://www.pcgamer.com/the-end-ofstar-wars-galaxies/. 